unit of cultivated land, and the index of agricultural output increased by about 12.5 per cent, compared with an average world increase during the same period of about 15.5 per cent. The production of rice, the staple food of the area's population, increased by about 40 per cent to more than 108 million tons in 1960, and that of maize by more than 30 per cent. Output of petroleum increased from 10.8 million tons to 26.5 million tons, of coal from 35 million tons to more than 54 million tons; steel production from about 1.3 million tons to more than 3 million tons; and of cement from less than 6 million tons to 10.8 million tons, while diversification is gradually being achieved both in agriculture and industry. Illiteracy is being reduced, and most countries aim at establishing universal primary education in the foreseeable future, while secondary and higher education are being rapidly promoted. Malaria is being eradicated, and health programmes have helped to mitigate the ravages of influenza, tuberculosis and other epidemics

Looking at the task ahead, particularly in the light of the increase in population during the decade 1950-60 from 595 million to 743 million, or 1.5 times that of the increase during $1920-50$, the report points out that while the objectives set out in 1950 have been shown to be correct, the task has proved even more formidable than was expected. The peoples of the region are aware that progress will continue to depend above all on their own efforts and determination and that external assistance, however massive, cannot replace those efforts. Apart, however, from this continuing need for popular understanding and support, the Governments of the region will continue to be faced with the need for resolute action to raise the standards of living, and in this priorities present special difficulty. The precise balance between investment in agriculture and in industry, of priorities within the agricultural and industrial sectors, between investment and consumption, between a lower level of education and training for the many and a higher level for the comparatively few will never be easy to determine. Beyond this there remains a challenge to the more developed countries within the limits of their resources to help the less-developed countries to help themselves. In doing so they will make the greatest possible contribution to the development and welfare of the region, but while external aid will remain an important factor in determining the degree of economic progress, the more-advanced countries must continue to adapt their methods and approach to changing circumstances. There are no simple solutions to the many problems that arise and pro. gress can only be made as difficulties are tackled in a continued spirit of goodwill and co-operation and on the basis of growing appreciation and understanding of each other's difficulties. The second, and largest. part of the report outlines the progress made in the individual member countries of the Plan in 1960 and during the decade $1950-60$, while in Part 3 are outlined some contributions to economic development in South and South-East Asia made by individual countries. United Kingdom Government expenditure on capital and technical assistance for development in South and South-East Asia during 1960-61 totalled $£ 35.9$ million, bringing the total of such expenditure under the Plan to $£ 182.78$ million, with outstanding commitments at June 30,1961 , of $£ 84 \cdot 13$ million (including the whole of the $£ 20.8$ million contribution to the Indus Basin Development Fund) to be paid over the period 1960-72. Expenditure of $\mathfrak{E 1 \cdot 1 4}$ million on technical assistance brought the total since 1951 to $£ 7.06$ million, and the 565 students in the United Kingdom undergoing training on June 30 . 1961, brought the total of Asian students who have received instruction in the United Kingdom under the Plan to 3,892 , and total expenditure for this purpose to $£ 3 \cdot 12$ million. The 42 experts provided during the year brought the total to 427 , and the $\mathbf{1 2 3 5 , 9 8 8}$ provided for equipment for training and research purposes brought the total under this head to $£ 2.01$ million. Capital aid expenditure during the year amounted to $\mathfrak{\$ 4} \cdot 76$ million, bringing the grand total under the Plan to $£ 175.72$ million, with outstanding commitments at June 30,1961 , of $£ 82.55$ million.

\title{
PLANT TISSUE AND ORGAN CULTURE
}

A

SYMPOSIUM on the above subject was organized under the joint auspices of the University of Delhi and of the South Asia Science Co-operation Office of Unesco, which is also at Delhi. These arrangements were made by Prof. P. Maheshwari on behalf of the University of Delhi and by Dr. J. Swarbrick on behalf of Unesco. The 38 active participants in the symposium are greatly indebted to its organizers for the opportunity so presented to discuss various aspects of this interesting and rapidly developing field of work, which was covered in 36 different papers presented to the symposium. These papers will be made more widely available in a symposium volume which is to be printed as a separate issue of the journal Phytomorphology.

Seven foreign delegates were able to participate in the conference under the arrangements made by Unesco. These delegates were: Dr. J. P. Nitsch (from Laboratoire de Phytotron, Gif-sur-Yvette), Prof. J. Reinert (Pflanzenphysiologisches Institut der Freien Universität, Berlin-Dahlem); Prof. H. E. Street (Department of Botany, University College of
Swansea), Prof. F. C. Steward (Cornell University, Ithaca, Now York), Dr. A. N. Rao (University of Malaya), Prof. B. L. T. de Silva (University of Colombo), Dr. Tun (University of Mandalay). The remainder of the delegates to the symposium were from different parts of India.

Four of the foreign delegates (Dr. Nitsch, Profs. Reinert, Steward and Street) delivered informative general lectures under the following titles: "The in vitro Culture of Flowers and Fruits" (Dr. J. P. Nitsch); "The Experimental Modification of Growth and Differentiation in Plant Tissue Cultures" (Prof. J. Reinert); "Carrots and Coconuts: Some Investigations on Growth" (Prof. F. C. Steward); "Nutritional Problems Raised by Work with Root Cultures" and "Studies on the Hormonal Control of Root Growth" (Prof. H. E. Street).

In addition, these delegates delivered other papers on more specialized subjects such as: carbohydrate nutrition of excised tomato roots (Prof. H. E. Street); naturally occurring growth substances in relation to the grow th of tissue cultures (Dr.J. P. Nitsch); and 
totipotency and variation in cultured plant cells (Prof. F. C. Steward). In this way these four foreign delegates presented to the symposium a broad picture of work in their respective fields and laboratories. This was further supplemented by two films in sound and colour, which had previously been recorded by Prof. F. C. Steward, and were shown under titles of "The Requirements for Growth in Plants" and Growth and Development of Plants".

The remaining papers fell into four main groups: (1) nine papers dealt with the culture of reproductive organs such as the nucellus (as in citrus), embryos. ovules, ovaries, flowers or pieces of inflorescence; (2) four papers on the culture of cryptogams, particularly fern gametophytes, the thalli of Marchantia, and on the culture of a moss (Physcomitrium coorgense); (3) four papers on the culture, mostly the technique of culture, of grown gall tumour tissue from the hollyhock (Althaea rosea); (4) four papers dealing with aspects of morphogenesis in tissue cultures of horseradish (Armoracia lapathifolia), of carrot root (Daucus carota), in orchid seedlings, and in Bryophyllum.

The conference drew heavily on the wealth of experimental morphological material which was available in the Department of Botany at Delhi, through the work of students working largely under the direction of Prof. P. Maheshwari and Dr. B. M. Johri as well as of other members of the Delhi staff. This Department, already well known for its contributions to plant morphology, has turned inereasingly in recent years to an experimental approach to morphological problems. The visitors to the confer tnce were impressed with the range of interesting plant material under investigation by these means. especially the examples of the culture of nucellus, ovules, ovaries, etc., and of other parts of the reproductive system. It is a healthy sign for plant morphology, and one from which physiology will also profit, that those already well trained in morphology are now bringing their skills to bear on the culture of selected and interesting plant parts. The published volume that will recount these various investigations may thus be anticipated as one which will significantly advance knowledge in this field. The hope also is that the conference will have stimulated interest in this subject in South-East Asia, even as it furnished the foreign delegates with a valued opportunity to see what is going on in India.

In fact, at the end of the Delhi symposium, Dr. Nitsch and Profs. Reinert, Steward, and Street went to the Indian Science Congress, held at Cuttack. where they were again received as foreign delegates and guests of the Congress. Dr. Nitsch and Profs. Street and Steward delivered special lectures to the Indian Science Congress on topies similar to those presented to the Delhi symposium; Prof. Steward also addressed the annual meeting of the Indian Society of Biological Chemists, on the "Soluble Nitrogen Compounds of Plants", and Profs. Street and Steward participated with the Indian Society of Plant Physiologists in a meeting specially devoted to honouring Prof. F. G. Gregory, whose recent death was especially regretted in India where there are so many plant physiologists who were trained by him.

The foreign delegates especially are deeply grateful to the University of Delhi, to Uneseo, and to the organizers of the Indian Science Congress for the opportunity to present an account of their own work and also to understand more about the range of experimental botanical work in progress in the various centres which they were able to visit. This left an impression of experimental plant morphology as a thriving branch of experimental science, which poses unique problems of growth and development for botanists to solve. In doing this work, elassically trained morphologists and biochemically trained physiologists can now usefully combine forces and so benefit their respective disciplines.

\section{TEXTILE RESEARCH AND COLOUR CHEMISTRY AT LEEDS}

\begin{abstract}
THE eighty-fifth and eighty-sixth reports of the Advisory Committee on Textile Industries and Colour Chemistry and Dyeing in the University of Leeds to the Worshipful Company of Clothworkers. covering the sessions $1958-59$ and 1959-60. record considerable progress *. In the Department of Textile Industries the number of students remained about 400 , but in 1958-59 extra-mural activities were an outstanding feature. In textile physics considerable progress was made in electron microseopic studies of various fibres. The uranyl group has been found to yive selective staining of the endo-cuticle, and it has also been shown that two intercellular layers of the cell-membrane complex are attacked by keratinolytic reagents and enzymes. The structural changes brought out by variations in the conditions under which filaments of polyacrylonitrile are spun have also been studied.
\end{abstract}

In textile chemistry, cross-linking and polymerization reactions continued to receive much attention.

* Reports to the Worshipful Company of Clothworkers of the City f London of the Advisory Committee on the Departments of Textile Industries and Colour Chemistry and Dyeing in the University of Leeds. Session 1958-59: Pp. 50; Session 1959-60: Pp. 52. (Leeds: The Unjversity.
The physical properties of wool fibres (elastic modulus. swelling ratio) have been correlated with theoretical predictions. It has also been shown that an oxidized and alkali-treated wool fibre shows reversible spontaneous contraction and extension as the $p \mathrm{H}$ of an ambient aqueous solution is altered, the thermodynamic and X-ray diffraction results corresponding closely to those observed with muscle preparations. New methods of forming anchored and unanchored polymers on and in wool fibres have been evolved, and promising results have been obtained with insoluble organic pigments in the low-temperature. solvent-assisted method of dyeing. The constitution of suint has been established as essentially a poly. merized dihydroxyphenol carrying a long-chain acid which can form peptide links with amino-compounds. The heat, free energy and entropy of sorption of methacrylic acid from aqueous solution by nylon have been determined, and the polymerization of methacrylic acid in nylon and the properties of nylon fabries containing this polymer are being examined. The thermodynamic functions of $\beta$-keratose fibres are being examined and also the setting proporties of wool, and the plasticity of wool has been related invorsely to the sulphur content of the $\beta$-keratose 